\title{
Synergic effect of vitamin A and high-fat diet in adipose tissue development and nuclear receptor expression in young rats
}

\author{
Anabelle Redonnet ${ }^{1}$, Carine Ferrand ${ }^{2}$, Céline Bairras ${ }^{1}$, Paul Higueret ${ }^{1}$, Catherine Noël-Suberville ${ }^{1}$, \\ Pierrette Cassand ${ }^{1}$ and Claude Atgie ${ }^{2 *}$ \\ ${ }^{1}$ Unité de Nutrition et Neurosciences (ISTAB), Université Bordeaux 1, Avenue des Facultés, Talence 33405, France \\ ${ }^{2}$ Laboratoire de Recherche du Département Universitaire des Sciences d'Agen (DUSA), Université Bordeaux 1, Avenue Michel \\ Serres, Agen 47000, France
}

(Received 7 June 2007 - Revised 20 December 2007 - Accepted 2 January 2008 - First published online 3 April 2008)

In order to study the effects of dietary lipids and vitamin A on the development of adipose tissues, young rats were submitted for $8 \mathrm{~d}$ to a control or to two cafeteria diets with normal (Caf) or higher $(\mathrm{Caf}+)$ vitamin A levels. Retinoid (retinoic acid receptor (RAR) $\alpha$, RAR $\gamma$, retinoid X receptor $(\mathrm{RXR}) \alpha$ ) and fatty acid (PPAR $\gamma$ ) receptor mRNA was measured in the subcutaneous white adipose tissue (Swat) and in isolated mature adipocytes by RT-PCR. The stroma vascular fraction was cultured in vitro to test the capacities of the adipocyte precursors to proliferate and differentiate. The Caf diet enriched in vitamin A resulted in an increased adiposity, due to increased adipocyte hypertrophy. This was concomitant with a lower expression of RAR $\alpha$ and RAR $\gamma$ mRNA $(-34.6$ and $-38.6 \%)$ and a higher expression of PPAR $\gamma(+59 \%)$ in the Swat and, to a less extent, in isolated adipocytes. Positive correlations were obtained between PPAR $\gamma$ mRNA and Swat weights and between PPAR $\gamma$ and RXR $\alpha$ mRNA. By contrast, RAR $y$ mRNA and Swat masses were negatively correlated. The adipocyte precursors from Caf + Swat proliferated more, in vitro, at the beginning of the culture. This difference progressively disappeared and was totally absent after $8 \mathrm{~d}$ of culture, but with a higher percentage of differentiated preadipocytes $(+80.3 \%)$ in the Caf + group. In conclusion, lipids and vitamin A act synergistically on the normal growth of the adipose tissue in young rats, concomitant with an imbalance in the pattern of the nuclear receptors. These changes influence the early normal development of the endogenous adipocyte precursors.

Diet-induced obesity: Peroxisome proliferator-activated receptor: Retinoic acid receptor: Retinoid X receptor: Adipogenesis

Today, it is clearly acknowledged that environmental factors and especially dietary factors may largely contribute to the development of obesity ${ }^{(1)}$. To study the implication of nutrients at the onset of obesity, most nutritional experiments are done using unbalanced hyperenergetic diets. One of the most commonly studied diets is the cafeteria-type diet, consisting of palatable high-fat, high-energetic food, that clearly mimics the diet of humans in the Western world, which has been responsible for the increase in obesity during the last decade ${ }^{(2-4)}$. Many studies performed on rats with this type of experimental diet show a rapid increase in fat storage, as a result of a clear imbalance between energy input and energy expenditure ${ }^{(5)}$.

Under these conditions, the increase in fat mass observed is the result of two morphological changes in the white adipose deposits. First, cell sizes increase rapidly due to excessive lipogenesis activity that leads to increased TAG storage in the lipid droplet. The number of cells per tissue also increases by a recruitment of precursors that proliferate and differentiate to form 'de novo' mature adipocytes ${ }^{(6-8)}$. The relative contribution of each phase to the development of adipose tissue depends on the nature of the diet, the time of treatment and the localisation of the adipose deposit ${ }^{(9)}$. This differentiation capacity of adipocyte precursors to form mature adipocytes, called adipogenesis, is a result of a complex process and is characterised by changes in cell morphology, hormone sensitivity and gene expression ${ }^{(10)}$. Many studies confirm that an excess of fatty acids, brought about by a high-fat diet, directly influences gene expression of the adipose tissue program through up-regulation of a key transcription factor: PPAR $\gamma^{(11)}$. However, fatty acids are not the only nutrient involved in the control of adipogenesis. Many other hormonal and nutritional factors could interact with this complex signalling pathway, and especially retinoic acid (RA), the active form of vitamin $\mathrm{A}^{(12)}$.

It is classically recognised that after the liver, adipose tissue is a major site of vitamin A storage and metabolism ${ }^{(13,14)}$. At the nuclear level, the different isoforms of RA, all-trans-RA and 9-cis-RA are able to bind the retinoic acid receptor (RAR), but only the 9-cis-RA binds equally well to RAR and retinoid $\mathrm{X}$ receptor $(\mathrm{RXR})^{(15)}$. These complexes are able to bind to specific sequences in the promoter region of their

Abbreviations: Caf, cafeteria diet with normal vitamin A levels; Caf + , cafeteria diet with higher vitamin A levels; DMEM-F12, Dulbecco's modified Eagle's medium; RA, retinoic acid; RAR, retinoic acid receptor; RXR, retinoid X receptor; Swat, subcutaneous white adipose tissue; Vwat, visceral white adipose tissue. * Corresponding author: Dr Claude Atgié, fax +33 5 53480641, email claude.atgie@u-bordeaux1.fr 
target genes. This regulation of transcriptional activity by retinoids plays a crucial role in the signalling pathway of many other factors and particularly in the fatty acid signalling pathway. Because PPAR and RAR need to form functional heterodimers with the same common partner, RXR, to bind to hormone response elements ${ }^{(16,17)}$, it appears that RA, via RXR, could interfere with the molecular action of fatty acids at the nuclear level in adipose tissue $e^{(18-20)}$.

Many studies, performed in vitro, have shown different actions of RA in the control of adipose tissue proliferation and differentiation $^{(21,22)}$. Classically, RA is considered as a powerful inhibitor of adipogenesis, when added at high doses during the early stage of adipocyte differentiation ${ }^{(23,24)}$. However, when lower doses are added before confluence, RA has been seen to activate adipocyte differentiation ${ }^{(25)}$. These differences could be explained by different impacts of RA in the regulation of this cascade of transcriptions factors involved in adipogenesis ${ }^{(14,26,27)}$

Furthermore, few studies have been performed in vivo to observe retinoid effects on the control of adipose tissue development in an 'adipogenic' situation, such as cafeteria diet exposure. Based on a previous study, where male adult rats were exposed for 8 weeks to two cafeteria-type diets containing different levels of vitamin A, it was observed that, despite a high increase in fat mass induced by the two cafeteria regimens, no marked difference was seen in the mRNA nuclear profile measured in two different deposits between the two groups of cafeteria diets ${ }^{(28)}$. Therefore, in the present study, we decided to expose younger rats to the same diets but for a shorter period of 1 week. Under these conditions, mRNA from subcutaneous white adipose tissue (Swat) and subcutaneous mature isolated adipocytes were extracted to measure the expression of nuclear receptor subtypes (PPAR $\gamma, \operatorname{RAR} \alpha$ and $\gamma, \operatorname{RXR} \alpha)$ and for a specific marker of adipocyte differentiation $\left(\mathrm{aP}_{2}\right)$. In the same experiment, the consequences of exposure to these different diets were tested on the capacities of adipocyte precursors from Swat to proliferate and differentiate during 1 week of primary culture.

\section{Experimental methods}

\section{Chemicals and reagents}

All products added to the culture medium and Dulbecco's modified Eagle's medium (DMEM-F12) were purchased from Sigma-Aldrich (Lyon, France), except for insulin, which was obtained from Novo Nordisk (Paris, France). The TRIzol reagent was obtained from Invitrogen (Cergy Pontoise, France). Serum TAG and cholesterol were measured using a bioMérieux assay kit (Marcy l'Etoile, France). Serum glucose and lactate were also measured using Sigma glucose and lactate kits. TAG accumulation in preadipocytes in culture was measured using a Boehringer analysis kit (Mannheim, Germany).

\section{Animals and methods}

All studies were performed on male Wistar rats weighing $50-70 \mathrm{~g}$ (age 3 weeks), obtained from Janvier (Le Genest St Isle, France). The use of animals was in accordance with the Institute for Laboratory Animal Research (ILAR) Guide for Care and Use of Laboratory Animals. The rats were housed two per cage with a $12 \mathrm{~h}$ light $-12 \mathrm{~h}$ dark cycle at $50 \%$ humidity and $24 \pm 1^{\circ} \mathrm{C}$. The rats were fed for a minimum $5 \mathrm{~d}$ of adaptation with a standard pellet diet (UAR, Paris, France). The animals were then housed individually to receive for 1 week the same standard pellet diet defined as the control diet or the two cafeteria diets with different vitamin A levels (Caf + and $\mathrm{Caf}$ ). These diets were prepared from a variety of highly palatable human food (bacon, chocolate, potato chips, biscuits and a pellet diet) containing liver pâté (for $\mathrm{Caf}+$ ) and ham pâté (for Caf). The $\mathrm{Caf}+$ and Caf diets contained respectively 10.4 and $12 \%$ proteins, 35.2 and $37.8 \%$ carbohydrates and 54.4 and $50.1 \%$ lipids. The main source of fat was bacon $(20 \mathrm{~g}$ per $100 \mathrm{~g}$ food). The calculated ratios of the $n$-6 PUFA $v . n$-3 PUFA were no different in the two diets. The cafeteria diet with the upper level of vitamin A $(\mathrm{Caf}+)$ contained $820 \mu \mathrm{g}$ retinol per $\mathrm{g}$ diet while the second cafeteria diet (Caf) contained $225 \mu \mathrm{g}$ retinol per $\mathrm{g}$ diet, the same as the control diet (UAR, Paris, France).

\section{Measurement of tissue samples and serum parameters}

At the end of the diet period $(8 \mathrm{~d})$, the rats were killed by decapitation. Blood was collected and centrifuged for $5 \mathrm{~min}$ at $5000 \mathrm{~g}$ at $4^{\circ} \mathrm{C}$. Serum were rapidly collected, and stored at $-80^{\circ} \mathrm{C}$ for measurement of biochemical parameters. The Swat, retroperitoneal, epididymal and visceral white adipose tissues (Vwat) were removed and weighed. Swat was washed in a cold saline solution $(\mathrm{NaCl}, 0.9 \%$; diethyl pyrocarbonate, $1 \%)$. Portions of Swat $(200 \mathrm{mg}$ ) were placed in TRIzol reagent (Invitrogen), and stored at $-80^{\circ} \mathrm{C}$ before nucleic acid extraction. Serum TAG and cholesterol were measured using a bioMérieux assay kit. Serum glucose and lactate were also measured using Sigma glucose and lactate kits. The serum retinol measurements were performed by an HPLC chromatographic method according to the NF EN 12823-1 standard.

\section{Isolation of subcutaneous adipocytes and culture conditions}

Swat were removed immediately after the animals were killed, washed several times with a DMEM-F12 medium and the majority of connective tissues and blood clots were removed. Mature adipocytes and the stroma vascular cells were then isolated according to the method previously described by Cousin et al. ${ }^{(29)}$ with some modifications. Briefly, Swat was minced into small fragments, which were digested with collagenase $(1 \mathrm{~g} / \mathrm{l})$ in a DMEM-F12 medium supplemented with serum bovine albumin $(3.5 \mathrm{~g} / \mathrm{l})$, in a shaking water-bath at $37^{\circ} \mathrm{C}$ for $45 \mathrm{~min}$ in a polypropylene flask. Cells were then filtered through nylon filters (100 and $30 \mu \mathrm{m}$ mesh). The suspension was then centrifuged at $1600 \mathrm{~g}$ for $10 \mathrm{~min}$ to separate the pelleted preadipocytes from the floating adipocyte fraction. The adipocyte fraction was counted using an automatic cell counter (Easycam Coulter; Beckman Coulter, Roissy, France), put into TRizol reagent and stored at $-80^{\circ} \mathrm{C}$ before nucleic acids extractions. The pellets of preadipocytes were then washed three times with DMEM-F12 culture medium and erythrocytes were discarded by contact for $3 \mathrm{~min}$ with a hypotonic haemolytic solution. Preadipocytes were suspended in DMEM-F12 medium, supplemented with $10 \%$ calf bovine serum, with antibiotic, and a solution of biotin $(17 \mu \mathrm{M})$, ascorbic acid $(100 \mu \mathrm{M})$, pantothenic acid $(17 \mu \mathrm{M})$ and ampothericin $(5 \mu \mathrm{M})$. 
Stroma vascular cells were counted with the Easycam Coulter and then cultured (500 000 cells per well) in polypropylene culture plates stored for $8 \mathrm{~d}$ in a humidified incubator (at $37^{\circ} \mathrm{C}$, under $5 \% \mathrm{CO}_{2}$ and $95 \% \mathrm{O}_{2}$ ). The following day (day 1), the culture medium was removed from each well of the plates, adherent cells rinsed with $2 \mathrm{ml}$ sterile phosphate buffer and the preadipocytes cultured in fresh DMEM-F12 containing $10 \%$ fetal calf serum and insulin (100 nM). Media were changed every $48 \mathrm{~h}$.

Measurement of preadipocyte proliferation activity. Between day 1 and day 8, proliferation activity of preadipocytes in culture was measured by counting the number of cells in three different wells after a trypsinisation procedure. Briefly, at day 1 , day 3 , day 5 and day 8 , the media were removed from three wells of each culture plate, and the adherent cells were rinsed with $2 \mathrm{ml}$ sterile phosphate buffer. Next, $0.5 \mathrm{ml}$ of a trypsin solution $(1 \%)$ was added for $3 \mathrm{~min}$ at $37^{\circ} \mathrm{C}$. The trypsin action was then stopped by adding $0.5 \mathrm{ml}$ of DMEM-F12 with $10 \%$ fetal calf serum. After 10 min of centrifugation at $1600 \mathrm{~g}$, the pellet was washed twice with phosphate buffer and the preadipocytes were counted.

Measurement of the differentiation level. On day 8 of the culture experiment, the differentiation levels of the preadipocytes were determined by measuring accumulated TAG in each well of the culture plates. Briefly, the culture media were removed; the cells rinsed twice with phosphate buffer and then scraped. After homogenisation in $1 \mathrm{ml}$ of phosphate buffer, TAG were measured using a Boehringer analysis kit.

\section{Quantification of messenger ribonucleic acid expression}

Total ribonucleic acid preparation. Portions of the adipose tissue $(200 \mathrm{mg})$ or adipocyte cells were homogenised in $1 \mathrm{ml}$ TRIzol reagent (Invitrogen, Cergy Pontoise, France) and total RNA was extracted according to the manufacturer's recommended instructions. The quality of total RNA was assessed using an off-the-shelf kit (RNA LabChip kit; Agilent Technologies, Meyrin, Switzerland) and an Agilent 2100 bioanalyser. Quantification was achieved by measuring light absorbency at $260 \mathrm{~nm}$. Average yield of total RNA extraction was not significantly different in tissues from $\mathrm{Caf}+$, Caf and the control groups.

Reverse transcription. cDNA was synthesised with ImpromII RT (Promega, Charbonnières-les-Bains, France) according to the manufacturer's recommended protocol, with modifications. Briefly, an amount of $1 \mu \mathrm{g}$ of total RNA was incubated with RNAsin Ribonuclease inhibitors (Promega) and with DNase-I (Roche Diagnostics, Meylan, France) $15 \mathrm{~min}$ at $37^{\circ} \mathrm{C}$ in order to degrade DNA and inhibit RNase. Then specific reverse primers $(120 \mathrm{ng})$ were added and incubated at $70^{\circ} \mathrm{C}$ for $10 \mathrm{~min}$. The RT reaction was performed at $42^{\circ} \mathrm{C}$ for $60 \mathrm{~min}$. Each target mRNA was co-reverse transcribed with $\beta 2$-microglobulin as housekeeping gene, relating to the level of expression of the quantified gene. Parallel reactions for each RNA samples were run in the absence of reverse-transcriptase to assess the degree of any contaminating genomic DNA.

Analysis of gene expression using real-time polymerase chain reaction. Analysis of gene expression using a realtime PCR (PCR assay employing a Light Cycler $^{\text {TM }}$ technology) $^{2}$ was carried out as described by Redonnet et al. ${ }^{(30)}$ with minor modifications specific to the gene studied. The forward and reverse primer sequences of $\beta 2$-microglobulin, $\operatorname{RAR} \alpha, \operatorname{RAR} \gamma$,
RXR $\alpha$ and PPAR $\gamma$ were described by Bairras et al. ${ }^{(28)}$ and amplification of $\mathrm{aP}_{2}$ was performed with the following primers: forward $5^{\prime}$ CCGAGATTTCCTTCAAACTGGG3' and reverse $5^{\prime}$ CCACCACCAGCTTGTCACCATC $3^{\prime}$. Specificity of primers was validated through the verification of RT-PCR product specificity. RT-PCR products were subjected to analysis by electrophoresis on a $1.5 \%$ agarose gel and resulted in a single product with the desired length. The identity of amplified products was verified by sequencing with the Dye Terminator Reaction Cycle Kit (Perkin-Elmer, Norwalk, CT, USA) and analysed on an ABI PRISM ${ }^{\mathrm{TM}} 377$ automated DNA sequencer (Perkin-Elmer).

$\beta 2$-Microglobulin cDNA was used as housekeeping for the relative quantification of cDNA of $\operatorname{RAR} \alpha, \operatorname{RAR} \gamma, \operatorname{RXR} \alpha$, PPAR $\gamma$ and $\mathrm{aP}_{2}$. The results were normalised by the ratio of the relative concentration of target to those of $\beta 2$-microglobulin sample. The real-time PCR method ensured that the expression level of the housekeeping gene was unaffected by the different diets.

\section{Statistical analysis}

All the results are presented as mean values with their standard errors. ANOVA and Fisher's positive least-significant difference post hoc test were performed using Statgraphic plus 5.1 software (StatPoint, Inc., Herndon, VA, USA) to assess the statistical significance. The correlation coefficient was determined by a linear model of regression analysis performed with the same statistical software. Statistical significance level was set at $P<0 \cdot 05$.

\section{Results}

Effects of $8 d$ of two cafeteria diets on body weight and energy intake

As shown in Table 1, all the animals in the three groups increased their body weight between the start (day 1) and end of treatment (day 8), but these increases were less significant in the two cafeteria groups (Caf and $\mathrm{Caf}+$ ) as compared with the control group. The total body-weight gains for the $\mathrm{Caf}+(47(\mathrm{SE} 1.9) \mathrm{g})$ and Caf (37 (SE 4.7) g) groups were significantly $(P<0.05)$ lower than those of the control group (72 (SE 4.4) g). The daily energy intakes at the start of the diet period (day 1$)$ were significantly $(P<0.05)$ higher in the two cafeteria groups as compared with the control group, but these differences disappeared on the last day of the diet period (day 8), where the daily energy intakes of the three groups of rats were not statistically different. The total energy intakes measured in the three groups of rats, for the $8 \mathrm{~d}$ of treatment, showed higher values in the two Caf groups compared with the control group, but this difference was much larger in the $\mathrm{Caf}+$ group than in the Caf group (26.3\% higher than control in the $\mathrm{Caf}+$ group; $18.6 \%$ higher than control in the Caf group; $P<0 \cdot 05)$.

Effects of $8 d$ of two cafeteria diets on serum triacylglycerol, cholesterol, glucose, lactate and retinol levels

As shown in Table 2, serum TAG levels were significantly higher $(91 \%)$ in the rats in the Caf + group compared with 
Table 1. Body weight and energy intake of the three groups of rats during $8 \mathrm{~d}$ of exposure to the different diets*

(Mean values with their standard errors for ten to twelve animals per group)

\begin{tabular}{|c|c|c|c|c|c|c|}
\hline & \multicolumn{2}{|c|}{ Control } & \multicolumn{2}{|c|}{ Caf } & \multicolumn{2}{|c|}{ Caf +} \\
\hline & Mean & SE & Mean & SE & Mean & SE \\
\hline Body weight (day 8) (g) & 170 & 3.7 & $142 \dagger$ & 3.9 & $147 \dagger$ & 3.4 \\
\hline$\Delta$ Body weight $(\%)$ & 72 & $4 \cdot 4$ & $37 \dagger$ & $4 \cdot 7$ & $47 \dagger$ & 1.9 \\
\hline $\mathrm{DEI}$ (day 1) (kJ/d) & 217 & $13 \cdot 4$ & 343† & $14 \cdot 2$ & $380 \dagger \ddagger$ & $15 \cdot 9$ \\
\hline DEI (day 8) (kJ/d) & 380 & $14 \cdot 3$ & 372 & $48 \cdot 4$ & 426 & 35.9 \\
\hline
\end{tabular}

Caf, cafeteria diet with normal vitamin A levels; Caf + , cafeteria diet with higher vitamin A levels; DEl, daily energy intake; TEI, total energy intake.

${ }^{*}$ For details of diets, see Experimental methods. Body weights were recorded at the beginning of the experiment (day 0 ) and at the end of the diet (day 8). Body-weight gains ( $\Delta$ body weight) were calculated as the difference between day 8 and day 0 . Daily energy intakes (DEI) were reported at the first day (day 1 ) and at the last day (day 8 ) of the treatment. Total energy intake (TEI) means the cumulated energy intake during the $8 \mathrm{~d}$ of the regimen.

† Mean value was significantly different from that of the control group $(P<0.05)$.

$\ddagger$ Mean value was significantly different from that of the Caf group $(P<0.05)$.

the two other experimental groups (Caf and control). The effects of the three different diets on the serum cholesterol levels were slightly different. In fact, as shown in Table 2, serum cholesterol levels were statistically higher (71 and $73.9 \%$ higher than control for $\mathrm{Caf}$ and $\mathrm{Caf}+$, respectively) in both the $\mathrm{Caf}$ and $\mathrm{Caf}+$ groups, without any significant difference between them. No significant effect of the three diets was observed on serum glucose and lactate levels (Table 2). After $8 \mathrm{~d}$ exposure to the cafeteria diet with the high level of vitamin A $(\mathrm{Caf}+)$, a slight increase in serum retinol level was induced (1.43 v. 1.29 and 1.24 for $\mathrm{Caf}$ and control respectively; see Table 2) but these differences did not reach statistical significance.

Effects of $8 d$ of two cafeteria diets on different white adipose deposit weights

Figure 1 shows that all the white adipose deposits were significantly higher in the two Caf groups than in the control group. However, these differences were greater in the subcutaneous and visceral adipose deposits of the $\mathrm{Caf}+$ group than in the Caf group $(P<0 \cdot 05)$. The total white adipose tissue, estimated by pooling all white adipose tissue removed, showed a significantly higher expansion in the $\mathrm{Caf}+$ group than in the Caf group.

Table 2. Effect of $8 \mathrm{~d}$ exposure to the three diets on serum biochemical parameters*

(Mean values with their standard errors for ten to twelve animals per group)

\begin{tabular}{|c|c|c|c|c|c|c|}
\hline & \multicolumn{2}{|c|}{ Control } & \multicolumn{2}{|c|}{ Caf } & \multicolumn{2}{|c|}{ Caf +} \\
\hline & Mean & SE & Mean & SE & Mean & SE \\
\hline TAG (mg/l) & 0.93 & 0.15 & $1 \cdot 21$ & 0.14 & $1 \cdot 78 \dagger \ddagger$ & 0.24 \\
\hline Cholesterol (mg/l) & 0.69 & 0.08 & $1 \cdot 18 \dagger$ & 0.06 & $1 \cdot 20 \dagger$ & 0.06 \\
\hline Glucose $(\mathrm{mmol} / \mathrm{l})$ & $6 \cdot 8$ & 0.38 & $7 \cdot 4$ & 0.32 & $6 \cdot 2$ & 0.22 \\
\hline Lactate $(\mu \mathrm{mol} / \mathrm{l})$ & 0.51 & 0.06 & 0.52 & 0.04 & 0.61 & 0.10 \\
\hline Retinol $(\mu \mathrm{mol} / \mathrm{l})$ & $1 \cdot 24$ & 0.08 & 1.29 & 0.13 & 1.43 & 0.09 \\
\hline
\end{tabular}

Caf, cafeteria diet with normal vitamin A levels; Caf + , cafeteria diet with highe vitamin A levels.

* For details of diets, see Experimental methods.

† Mean value was significantly different from that of the control group $(P<0 \cdot 05)$.

$\ddagger$ Mean value was significantly different from that of the Caf group $(P<0.05)$.
Effects of $8 d$ of two cafeteria diets on subcutaneous adipocyte sizes and numbers and on stroma vascular cells numbers

Figure 2 (a) shows the total lipid content of isolated adipocytes from the Swat. This parameter was chosen as an index of cell size. We observed that adipocytes isolated from the Caf + and Caf groups were larger than those isolated from the Swat of the control rats (320 and $430 \%$ larger cell size for Caf and $\mathrm{Caf}+$ compared with control, respectively; $P<0 \cdot 001)$. However, the results in Fig. 2 (b) show that the two Caf diets caused no change in the number of subcutaneous mature adipocytes and stroma vascular cells compared with the number of these same cell populations in the control group.

\section{Effects of $8 d$ of two cafeteria diets on nuclear receptor expression in subcutaneous white adipose tissue}

Results of nuclear receptor mRNA levels are shown in Fig. 3. Compared with the control group, PPAR $\gamma$ mRNA levels were significantly higher in the $\mathrm{Caf}+$ group only $(+59.5 \%$; $P<0.05)$ and $\mathrm{aP}_{2}$ mRNA levels were significantly higher in the Caf group $(+170 ; P<0.05)$ and $\mathrm{Caf}+$ group $(+235 \%$; $P<0.0005)$. Thus, the $\mathrm{Caf}$ group rats had a lower $\mathrm{aP}_{2}$

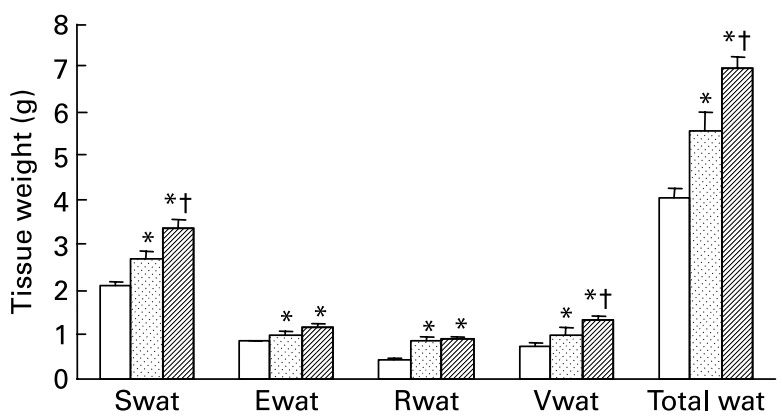

Fig. 1. Effect of $8 d$ exposure to the three diets (control diet ( $\square$ ), cafeteria diet with normal vitamin A levels (Caf; $\square$ ), cafeteria diet with higher vitamin A levels $(\square)$ ) on the subcutaneous (Swat), epididymal (Ewat), retroperitoneal (Rwat), visceral (Vwat) and total (Total wat) white adipose tissue weights. Values are the means of ten to twelve animals per group, with standard errors represented by vertical bars. * Mean value was significantly different from that of the control group $(P<0.05)$. † Mean value was significantly different from that of the Caf group $(P<0.05)$ 

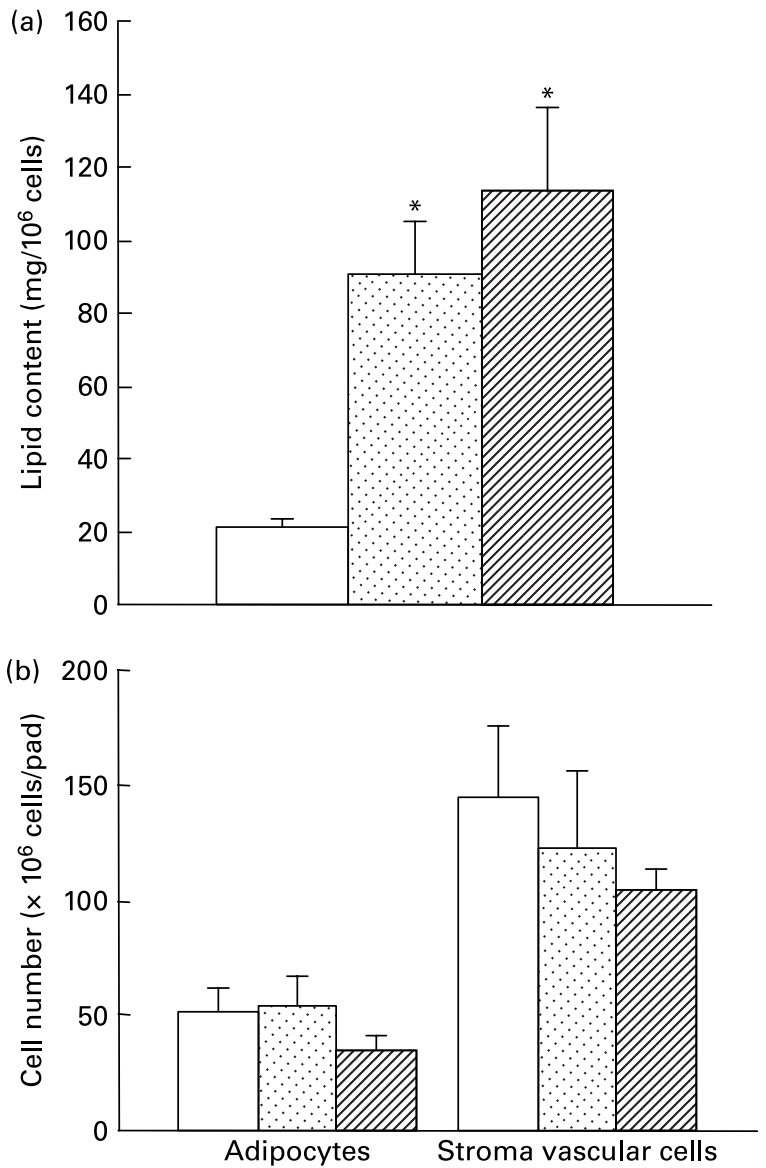

Fig. 2. (a) Total lipid isolated from mature adipocytes (see Experimental methods) of the subcutaneous white adipose tissue (Swat) of young rats after $8 \mathrm{~d}$ exposure to the three different diets (control diet $(\square)$, cafeteria diet with normal vitamin A levels $(\square)$, cafeteria diet with higher vitamin A levels $(\boldsymbol{Z})$ ). Results are expressed as $\mathrm{mg}$ lipid $/ 10^{6}$ cells. (b) Numbers of total adipocytes and stroma vascular cells (adipocyte precursors) isolated from the Swat of rats. Results are expressed as $\times 10^{6}$ cells per tissue. Values are the means of ten to twelve animals per group, with standard errors represented by vertical bars. *Mean value was significantly different from that of the control group $(P<0.05)$.

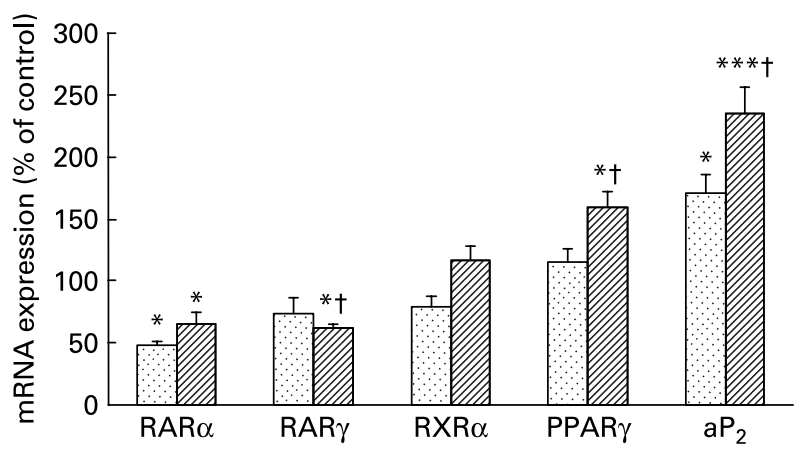

Fig. 3. Effect of $8 \mathrm{~d}$ exposure to the three diets (control diet, cafeteria diet with normal vitamin A levels (Caf; $\square$ ), cafeteria diet with higher vitamin A levels $(\mathrm{Caf}+; \mathbb{Z})$ ) on retinoic acid receptor (RAR) $\alpha$, RAR $\gamma$, retinoid $X$ receptor (RXR) $\alpha$, PPAR $\gamma$ and $\mathrm{aP}_{2}$ mRNA levels in the rat subcutaneous white adipose tissue. Results are expressed as percentages of the control data. Values are means ( $n 6$ per group) for the Caf and Caf + groups, with standard errors represented by vertical bars. Mean value was significantly different from that of the control group: ${ }^{*} P<0.05$, ${ }^{\star * \star} P<0.0005$. † Mean value was significantly different from that of the Caf group $(P<0.05)$.
mRNA level compared with the Caf + groups. In addition, as shown in Fig. 4 (a), the PPAR $\gamma$ mRNA level and the weight of Swat were positively correlated for each rat $(r$ 0.648; $P<0 \cdot 005)$.

Determination of the expression of $\operatorname{RXR} \alpha$ showed no significant change after $8 \mathrm{~d}$ of feeding. However, a positive correlation $(r$ 0.676; $P<0.005)$ was found between $\mathrm{RXR} \alpha$ and PPAR $\gamma$ mRNA levels, regardless of the group considered, in Swat of rats (Fig. 4 (b)).

RAR $\alpha$ and RAR $\gamma$ mRNA levels were significantly lower $(-34.6$ and $-38.5 \%$, respectively; $P<0.05)$ in the Caf + group than those of the control group. In the Caf group, only the RAR $\alpha$ mRNA level was significantly lower $(-52 \% ; P<0 \cdot 005)$ compared with the control rats. Compared with $\mathrm{Caf}+$ and control groups, the Caf rats exhibited an intermediate value of RAR $\alpha$ mRNA, but it did not reach
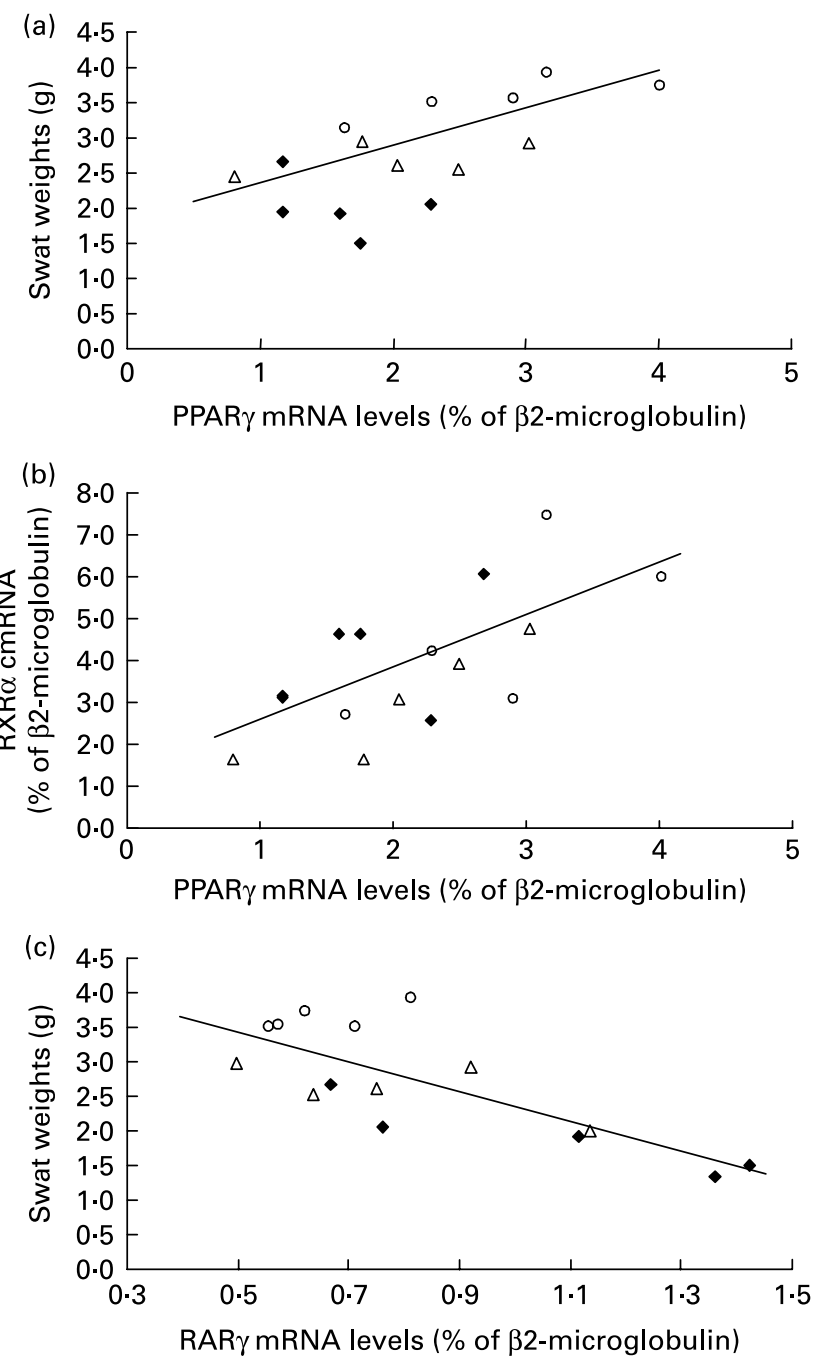

Fig. 4. Relationships between subcutaneous white adipose tissue (Swat) weights and nuclear receptor expression in control rats $(\bullet ; n 5)$, rats fed a cafeteria diet with normal vitamin $A$ levels $(\Delta ; n 5)$ and rats fed a cafeteria diet with higher vitamin A levels $(O ; n 5)$. (a) Correlation between PPAR $\gamma$ mRNA levels and Swat weight $(r 0.648 ; P<0.005)$. (b) Correlation between PPAR $\gamma$ mRNA levels and retinoid $X$ receptor (RXR) $\alpha$ levels ( $r$ 0.676; $P<0.005)$. (c) Correlation between retinoic acid receptor (RAR) $\gamma$ mRNA levels and Swat weight $(r-0.776 ; P<0.001)$. 
significance. However, a significant negative correlation $(r-0.776 ; P<0.001)$ was found between RAR $\gamma$ mRNA and the Swat weight in each rat (Fig. 4 (c)).

\section{Effects of $8 d$ of two cafeteria diets on nuclear receptor} expression in isolated adipocytes

Figure 5 shows that PPAR $\gamma$ mRNA level was lower in the Caf group as compared with the control group (-38.9\%; $P<0.05)$. No difference was found between the $\mathrm{Caf}+$ and control groups, but the Caf group had a lower PPARy mRNA level compared with the $\mathrm{Caf}+$ group $(P<0.05)$. Thus, $\mathrm{aP}_{2}$ mRNA level was $46.5 \%$ higher in the Caf + group relative to the control group $(P<0.005)$. The relative abundance of the Caf group $\mathrm{aP}_{2}$ mRNA was not significantly different from that of the control group but was significantly lower than that of the $\mathrm{Caf}+$ group.

The amount of RXR $\alpha$ mRNA was different between the Caf and control group rats $(-42 \% ; P<0.0005)$ and was lower in the Caf group $v$. the Caf + group. As in the Swat, we found a positive correlation between mRNA levels of PPAR $\gamma$ and $\mathrm{RXR} \alpha$ in isolated adipocytes of all rats $(r 0.649 ; P<0.01)$ (Fig. 6).

We also observed significantly lower RAR $\alpha$ mRNA levels in the Caf $(-39.2 \% ; P<0.005)$ and $\mathrm{Caf}+$ groups $(-30 \%$; $P<0.05)$ compared with the control group. However, the amount of RAR $\gamma$ was not affected in the isolated adipocytes.

Effects of $8 d$ of two cafeteria diets on the proliferation and differentiation capacities of subcutaneous adipocyte precursors in culture conditions

As shown in Fig. 7 (a), the number of preadipocytes derived from the precursors of each Swat was increased (approximately $2-2.5$-fold) during the $8 \mathrm{~d}$ of primary culture under our in vitro conditions. However, the kinetics of this increase in the number of cultured cells was different depending on the experimental group considered. On day 1 of culture,

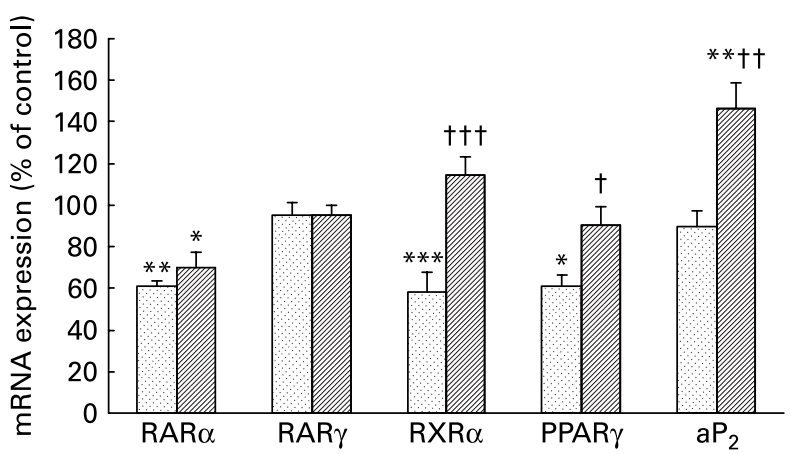

Fig. 5. Effect of $8 \mathrm{~d}$ exposure to the three diets (control diet, cafeteria diet with normal vitamin A levels (Caf; $\square$ ), cafeteria diet with higher vitamin $A$ levels $(\mathrm{Caf}+;(\mathbb{Z}))$ on nuclear receptor and $\mathrm{aP}_{2}$ mRNA expression in subcutaneous isolated adipocytes. Levels of retinoic acid receptor (RAR) $\alpha, \operatorname{RAR} \gamma$, retinoid $\mathrm{X}$ receptor $(\mathrm{RXR}) \alpha$, PPAR $\gamma$ and $\mathrm{aP}_{2}$ mRNA in rat mature adipocytes. Results are expressed as percentages of the control data. Values are means ( $n 7$ per group) for the Caf and Caf + groups, with standard errors represented by vertical bars. Mean value was significantly different from that of the control group: ${ }^{*} P<0.05,{ }^{* *} P<0.005,{ }^{* * *} P<0.0005$. Mean value was significantly different from that of the Caf group: $\dagger P<0.05$, $\dagger \dagger P<0.005$, ††† $P<0.0005$

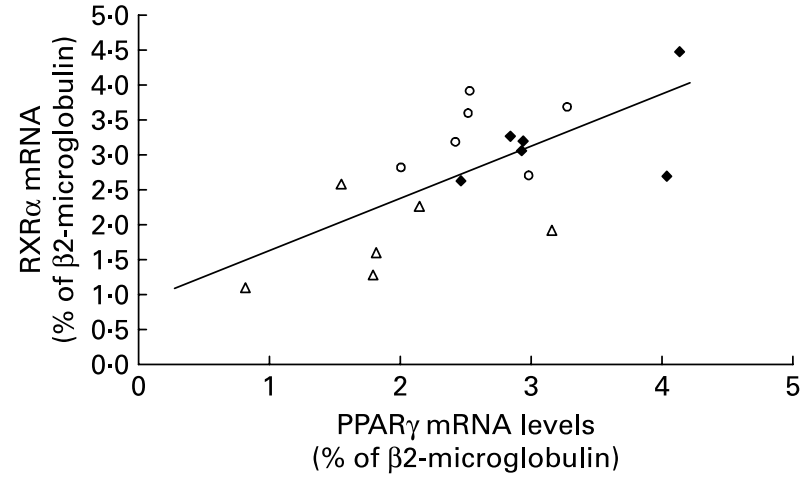

Fig. 6. Relationship between PPAR $\gamma$ and retinoid $X$ receptor (RXR) $\alpha$ mRNA levels in isolated adipocytes in control rats $(\bullet ; n 5)$, rats fed a cafeteria diet with normal vitamin $\mathrm{A}$ levels $(\triangle ; n 5)$ and rats fed a cafeteria diet with higher vitamin A levels $(O ; n 5)(r 0.649 ; P<0.01)$

(a)

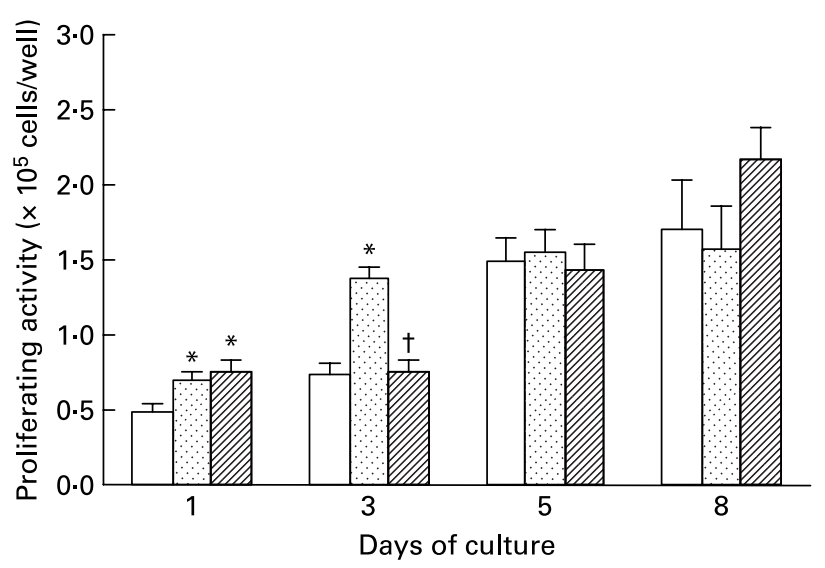

(b)

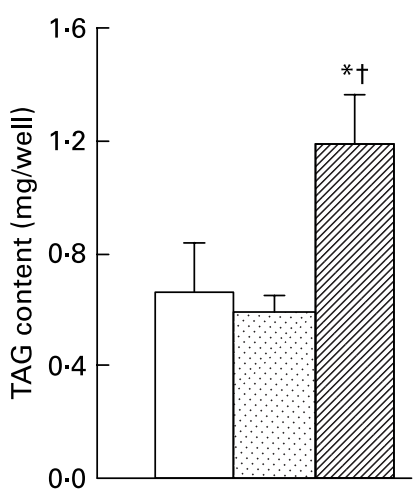

Fig. 7. Effect of $8 d$ exposure to the three diets (control diet ( $\square$ ), cafeteria diet with normal vitamin A levels (Caf; $\square$ ), cafeteria diet with higher vitamin A levels $(\mathbb{Z})$ ) on the proliferating activity (a) and differentiation level (b) of subcutaneous adipocyte precursors in culture. Precursor adipocyte cells, isolated from the subcutaneous white adipose tissue of rats, were cultured in vitro (see Experimental methods). The numbers of cells at 1,3,5 and $8 \mathrm{~d}$ of culture are reported. (a) Results are expressed as $\times 10^{5}$ cells per well of culture. (b) The levels of differentiation at $8 \mathrm{~d}$ of culture were estimated by the measurement of TAG accumulation in the preadipocyte (see Experimental methods). Results are expressed as mg TAG per well. Values are the means of six to eight animals per group, with standard errors represented by vertical bars. * Mean value was significantly different from that of the control group $(P<0.05)$. † Mean value was significantly different from that of the Caf group $(P<0.05)$ 
the number of cells in the culture plates was significantly higher $(P<0.05)$ in the two Caf groups as compared with the control group (Fig. 7 (a)). On the third day of culture (day 3), this increase in proliferation activity was accentuated only in the Caf group, in which the number of cells doubled as compared with the $\mathrm{Caf}+$ and control groups. On day 5 and day 8 of the primary culture experiments, corresponding to the submaximal and maximal proliferation activities, no difference was observed in the number of preadipocytes derived from the adipocyte precursors from the Swat of the three experimental groups.

After $8 \mathrm{~d}$ of culture, the level of accumulated intracellular TAG (chosen as an index of the differentiation activity) was significantly higher (Fig. 7(b)) in the Caf + preadipocytes than in the Caf and control preadipocytes $(80.3 \%$ higher; $P<0 \cdot 05)$, suggesting a higher degree of differentiation.

\section{Discussion}

The purpose of the present study was to investigate the change in adipose tissue nuclear profile of young rats exposed to a short period of cafeteria diets with normal or higher levels of vitamin A. Exposure during $8 \mathrm{~d}$ to these types of diet rapidly affected lipid status, since increased serum cholesterol was observed as already reported in our previous study ${ }^{(31)}$. Moreover, we noticed an increase in TAG levels that seemed more pronounced in the $\mathrm{Caf}+$ group. This observation could be attributed to an effect of vitamin A supplementation on liver lipid metabolism leading to a marked hyperlipidaemia. However, the retinol levels, measured in our conditions, did not change in the three groups. According to the studies of Périquet et al. ${ }^{(32)}$, the lack of change could be normal, because serum retinol level is not a good index of change in vitamin A status, even after a high supplementation. Despite this marked increase of lipidaemia, neither blood glucose nor lactate levels were affected by the $8 \mathrm{~d}$ with Caf or Caf + treatments. This observation led us to conclude that a short period of cafeteria exposure, with or without elevated levels of vitamin A, did not alter the insulin sensitivity, considering that a change in blood lactate level could indirectly underline a change in insulin action on glucose metabolism ${ }^{(33)}$.

Exposure for $8 \mathrm{~d}$ to the cafeteria diets was sufficient to induce a significant hyperphagia. This increase in food intake was classically observed after a short period of hyperlipidaemic, hyperenergetic food consumption ${ }^{(34)}$. However, it was interesting to note a more pronounced effect of the vitamin A-rich cafeteria diet. This may be due to the palatable aspect of this food made with liver pâté rather than to a direct action of vitamin A on the mechanism of food intake regulation, despite the fact that RA could act directly in the hypothalamus to inhibit the neuropeptide Y (NPY) action by downloading the NPY receptors ${ }^{(35)}$.

Despite this marked increase in total energy intake, all the animals in both Caf groups (either $\mathrm{Caf}+$ or Caf) showed a $30-40 \%$ deficit in normal body-weight gain, corresponding to $8 \mathrm{~d}$ of feeding in this growth period, during which control rats doubled their body weight.

However, all of the animals in both cafeteria groups increased their total fat mass, but the $\mathrm{Caf}+$ diet had a more pronounced effect on the Swat and Vwat. These two deposits are classically considered to be more directly involved in the metabolic adaptation to nutritional changes ${ }^{(36)}$, and are more susceptible to grow in response to an increase in energy intake. These results therefore suggest that a cafeteria diet could certainly influence the normal regulation of the energetic metabolism, inducing increased fat deposition rather than increased lean mass. It has been demonstrated that exposure of young rats during a growth period to a cafeteria diet could change body weight and tissue composition through an imbalance in $\mathrm{N}$ metabolism and amino acid metabolism ${ }^{(37,38)}$, and of course through a change in lean mass growth. A significant decrease observed in several muscles masses supports this hypothesis (data not shown).

It could be speculated that the positive action of the Caf + diet in the Swat and Vwat growth may be explained as an indirect consequence of the increased energy intake. Diet-induced thermogenesis, which is the main adaptative mechanism to regulate this imbalance of the energetic metabolism, could be saturated in the Caf + -exposed animals. Indeed, higher interscapular brown adipose deposits, with a paler brown colour, were observed in the animals from the $\mathrm{Caf}+$ group (data not shown), suggesting hypertrophied tissues, with deficient thermogenesis activities. Moreover, it has also recently been demonstrated that vitamin A, through its active form RA, is able to directly modulate leptin synthesis in adipose tissue, and that change in circulating leptin levels could directly influence the regulation of food intake and energy metabolism ${ }^{(39)}$.

However, it was surprising to note that, under our experimental conditions, a high level of vitamin $\mathrm{A}$ in the diet led to an increase in fat mass, whereas most works conclude that adipose tissue is increased in a situation of vitamin A deficiency in mice and that administration of RA leads to significant reduction of the adipose deposits ${ }^{(12,40)}$. On the other hand, Rodriguez et al. ${ }^{(41)}$ reported in a recent study that 4-week-old rats exposed for 2 weeks to a cafeteria diet consisting of liver pâté (equivalent to our $\mathrm{Caf}+$ group) markedly increased their Swat and Vwat adipose deposits.

When we considered only the change observed in the Swat, it appeared that the observed increase in mass could mainly be associated with cellular hypertrophy, with no change in stroma vascular cell population. These results confirm that $8 \mathrm{~d}$ of exposure to the two different cafeteria diets was too brief to increase the number of adipose cells in the Swat. This was classically observed upon the onset of obesity in rodents by exposure to a high-fat hyperenergetic diet ${ }^{(42)}$. Together with these changes in subcutaneous adipose cell size, induced by the two cafeteria diets, we found significant variations in the pattern of nuclear receptor expressions for the retinoic (RAR and RXR) and fatty acids (PPAR). These changes observed under our experimental conditions were more pronounced that those we previously reported with longer diet exposures of adult rats ${ }^{(28,31)}$. Indeed, the previously characterised decreases in both subtypes (RAR $\alpha$ and RAR $\gamma$ ) involved in the signalling pathway of the all-trans- $\mathrm{RA}^{(31)}$ were once again observed, concomitantly with an increase in PPAR $\gamma$ expression, with the highest effect observed in the Caf + group. So, in this group, the results of $\operatorname{RAR} \alpha$ and RAR $\gamma$ reductions and PPAR $\gamma$ up-regulation were combined with a much higher global differentiation level of the tissue, as attested by a higher expression of measured $\mathrm{aP}_{2}$. These results are in accordance with the commonly recognised inhibitory action of the RAR pathway on the adipogenesis program ${ }^{(23)}$. 
Our correlation analysis clearly supported the hypothesis that the overall changes in the balance between RA and fatty acid pathways were strongly dependent on the differentiation level of the tissue, and that the $\mathrm{RXR} \alpha$ receptor variation was also strongly dependent on those of the PPAR $\gamma$ receptors.

The observation of the same nuclear receptor expression profile in the isolated adipocytes from the Swat of the three experimental groups revealed more attenuated variations than in the whole tissue, with, in addition, specific differences induced by the two cafeteria diets. The effects observed on the RAR subtypes were less pronounced and only significant differences remained for the RAR $\alpha$ subtype. We could try to explain these differences between the overall adipose tissue and the functional mature adipocytes by a possible selection of the largest adipocyte population by the enzymic dissociation procedure. These hypertrophied adipocytes were undoubtedly in a terminal differentiation state, and, as a result, it was not surprising to observe a marked down-regulation of PPAR $y$ and $\mathrm{aP}_{2}$, which are classically considered as early differentiation markers. However, it was interesting to note that significant differences remained between the nuclear receptor expression profiles of isolated adipocytes from $\mathrm{Caf}+$ and $\mathrm{Caf}$ groups.

Our tests performed on primary cultures were very interesting because they confirmed that a change in nutrient availability surrounding the adipose precursors in situ could induce profound changes in their capacity to proliferate and differentiate under in vitro conditions, and of course in situ in a longer exposure to cafeteria diets. These early changes revealed by culture conditions could be directly induced by a direct retinoic action on these cells in situ or by indirect action after a change in paracrine signals that could influence their genetic program. It was logical to postulate, according to recent observations by Ribot et al. ${ }^{(43)}$, that a slight change in the RA signalling pathway could directly influence the normal regulation of the cell cycle program. Moreover, it was also possible that very early action of RA on the stroma vascular cells could increase the number of stem cells engaged in the adipoblast cell line ${ }^{(44)}$.

In conclusion, in young growing rats, brief exposure to a cafeteria diet can lead to a marked imbalance in the pattern of retinoid and fatty acid nuclear receptors of subcutaneous adipose deposits. These changes seem to be directly or indirectly dependent on the level of vitamin $\mathrm{A}$ in the diet and are strongly correlated to the adipose differentiation level. These results underline that the adipocyte precursors in the tissue are very sensitive to changes in their environment, and that differences in nutrient availability could influence their development capacities. More experiments need, of course, to be performed to better understand the molecular mechanism involved in these adaptations.

\section{Acknowledgements}

C. B. was the recipient of a doctoral fellowship from the MENRT (French Ministry of Education, Research and Technology). The study was supported by the CTP Network (Communauté de Travail des Pyrénées).

All the authors have nothing to declare and contributed equally to the manuscript. There are no conflicts of interest.

\section{References}

1. Comuzzie AG \& Allison DB (1998) The search for human obesity genes. Science 280, 1374-1377.

2. Astrup A, Buemann B, Western P, Toubro S, Raben A \& Christensen NJ (1994) Obesity as an adaptation to a high-fat diet: evidence from a cross-sectional study. Am J Clin Nutr 59, 350-355.

3. Lissner L \& Heitmann BL (1995) The dietary fat:carbohydrate ratio in relation to body weight. Curr Opin Lipidol 6, 8-13.

4. Lichtenstein AH, Kennedy E, Barrier P, Danford D, Ernst ND, Grundy SM, Leveille GA, Van Horn L, Williams CL \& Booth SL (1998) Dietary fat consumption and health. Nutr Rev 56, S3-S28.

5. Llado I, Estrany ME, Rodriguez E, Amengual B, Roca P \& Palou A (2000) Effects of cafeteria diet feeding on $\beta 3$-adrenoceptor expression and lipolytic activity in white adipose tissue of male and female rats. Int J Obes Relat Metab Disord 24, 1396-1404.

6. Faust IM, Johnson PR, Stern JS \& Hirsch J (1978) Diet-induced adipocyte number increase in adult rats: a new model of obesity. Am J Physiol 235, E279-E286.

7. Spiegelman BM \& Flier JS (1996) Adipogenesis and obesity: rounding out the big picture. Cell 87, 377-389.

8. Mandrup S \& Lane MD (1997) Regulating adipogenesis. J Biol Chem 272, 5367-5370.

9. Sclafani A \& Gorman AN (1977) Effects of age, sex, and prior body weight on the development of dietary obesity in adult rats. Physiol Behav 18, 1021-1026.

10. Gregoire FM, Smas CM \& Sul HS (1998) Understanding adipocyte differentiation. Physiol Rev 78, 783-809.

11. Lowell BB (1999) PPAR $\gamma$ : an essential regulator of adipogenesis and modulator of fat cell function. Cell 99, 239-242.

12. Bonet ML, Ribot J, Felipe F \& Palou A (2003) Vitamin A and the regulation of fat reserves. Cell Mol Life Sci 60, 1311-1321.

13. Tsutsumi C, Okuno M, Tannous L, Piantedosi R, Allan M, Goodman DS \& Blaner WS (1992) Retinoids and retinoid-binding protein expression in rat adipocytes. J Biol Chem 267, $1805-1810$.

14. Villarroya F, Iglesias R \& Giralt M (2004) Retinoids and retinoid receptors in the control of energy balance: novel pharmacological strategies in obesity and diabetes. Curr Med Chem 11, 795-805.

15. Love JD, Gooch JT, Benko S, Li C, Nagy L, Chatterjee VK, Evans RM \& Schwabe JW (2002) The structural basis for the specificity of retinoid-X receptor-selective agonists: new insights into the role of helix H12. J Biol Chem 277, $11385-11391$.

16. Chambon P (1996) A decade of molecular biology of retinoic acid receptors. FASEB J 10, 940-954.

17. Aranda A \& Pascual A (2001) Nuclear hormone receptors and gene expression. Physiol Rev 81, 1269-1304.

18. Ribot J, Felipe F, Bonet ML \& Palou A (2001) Changes of adiposity in response to vitamin A status correlate with changes of PPAR $\gamma 2$ expression. Obes Res 9, 500-509.

19. Kliewer SA, Umesono K, Noonan DJ, Heyman RA \& Evans RM (1992) Convergence of 9-cis retinoic acid and peroxisome proliferator signalling pathways through heterodimer formation of their receptors. Nature 358, 771-774.

20. Miyata KS, McCaw SE, Marcus SL, Rachubinski RA \& Capone JP (1994) The peroxisome proliferator-activated receptor interacts with the retinoid $\mathrm{X}$ receptor in vivo. Gene 148, 327-330.

21. Chawla A \& Lazar MA (1994) Peroxisome proliferator and retinoid signaling pathways co-regulate preadipocyte phenotype and survival. Proc Natl Acad Sci U S A 91, 1786-1790. 
22. Suryawan A \& Hu CY (1997) Effect of retinoic acid on differentiation of cultured pig preadipocytes. J Anim Sci 75, $112-117$.

23. Stone RL \& Bernlohr DA (1990) The molecular basis for inhibition of adipose conversion of murine 3T3-L1 cells by retinoic acid. Differentiation 45, 119-127.

24. Xue JC, Schwarz EJ, Chawla A \& Lazar MA (1996) Distinct stages in adipogenesis revealed by retinoid inhibition of differentiation after induction of PPAR $\gamma$. Mol Cell Biol 16, $1567-1575$.

25. Safonova I, Darimont C, Amri EZ, Grimaldi P, Ailhaud G, Reichert U \& Shroot B (1994) Retinoids are positive effectors of adipose cell differentiation. Mol Cell Endocrinol 104, 201-211.

26. Schwarz EJ, Reginato MJ, Shao D, Krakow SL \& Lazar MA (1997) Retinoic acid blocks adipogenesis by inhibiting C/EBP $\beta$-mediated transcription. Mol Cell Biol 17, 1552-1561.

27. Hida Y, Kawada T, Kayahashi S, Ishihara T \& Fushiki T (1998) Counteraction of retinoic acid and 1,25-dihydroxyvitamin D3 on up-regulation of adipocyte differentiation with PPAR $\gamma$ ligand, an antidiabetic thiazolidinedione, in 3T3-L1 cells. Life Sci 62, PL205-PL211.

28. Bairras C, Menard L, Redonnet A, Ferrand C, Delage B, NoelSuberville C, Atgie C \& Higueret P (2005) Effect of vitamin A content in cafeteria diet on the expression of nuclear receptors in rat subcutaneous adipose tissue. $J$ Physiol Biochem 61, $353-361$

29. Cousin B, Munoz O, Andre M, Fontanilles AM, Dani C, Cousin JL, Laharrague P, Casteilla L \& Penicaud L (1999) A role for preadipocytes as macrophage-like cells. FASEB $J$ 13, 305-312.

30. Redonnet A, Bonilla S, Noel-Suberville C, Pallet V, Dabadie H, Gin H \& Higueret P (2002) Relationship between peroxisome proliferator-activated receptor $\gamma$ and retinoic acid receptor $\alpha$ gene expression in obese human adipose tissue. Int $J$ Obes Relat Metab Disord 26, 920-927.

31. Redonnet A, Groubet R, Noel-Suberville C, Bonilla S, Martinez A \& Higueret P (2001) Exposure to an obesity-inducing diet early affects the pattern of expression of peroxisome proliferator, retinoic acid, and triiodothyronine nuclear receptors in the rat. Metabolism 50, 1161-1167.

32. Périquet B, Bailly A, Periquet A, Ghisolfi J \& Thouvenot JP (1985) Evidence for two subcellular pools and different kinetic behavior of retinyl palmitate in rat liver. Int $J$ Vitam Nutr Res $\mathbf{5 5}, 245-251$.

33. Lovejoy J, Newby FD, Gebhart SS \& Digirolamo M (1992) Insulin resistance in obesity is associated with elevated basal lactate levels and diminished lactate appearance following intravenous glucose and insulin. Metabolism 41, 22-27.

34. Prats E, Monfar M, Castella J, Iglesias R \& Alemany M (1989) Energy intake of rats fed a cafeteria diet. Physiol Behav 45, 263-272.

35. Mannon PJ \& Kaiser LM (1997) Retinoic acid is a negative regulator of the neuropeptide Y/peptide YY Y1 receptor gene in SK-N-MC cells. $J$ Neurochem $\mathbf{6 8}, 20-25$.

36. Wajchenberg BL (2000) Subcutaneous and visceral adipose tissue: their relation to the metabolic syndrome. Endocr Rev 21, 697-738.

37. Gianotti M, Roca P \& Palou A (1988) Body weight and tissue composition in rats made obese by a cafeteria diet. Effect of 24 hours starvation. Horm Metab Res 20, 208-212.

38. Esteve M, Rafecas I, Remesar X \& Alemany M (1992) Nitrogen balance discrepancy in Wistar rats fed a cafeteria diet. Biochem Int 26, 687-694.

39. Kumar MV, Sunvold GD \& Scarpace PJ (1999) Dietary vitamin A supplementation in rat: suppression of leptin and induction of UCP1 mRNA. J Lipid Res 40, 824-829.

40. Mercader J, Ribot J, Murano I, Felipe F, Cinti S, Bonet ML \& Palou A (2006) Remodeling of white adipose tissue after retinoic acid administration in mice. Endocrinology 147, $5325-5332$.

41. Rodriguez E, Ribot J, Rodriguez AM \& Palou A (2004) PPAR$\gamma 2$ expression in response to cafeteria diet: gender- and depotspecific effects. Obes Res 12, 1455-1463.

42. Woods SC, Seeley RJ, Rushing PA, D'Alessio D \& Tso P (2003) A controlled high-fat diet induces an obese syndrome in rats. $J$ Nutr 133, 1081-1087.

43. Ribot J, Oliver P, Serra F \& Palou A (2005) Retinoic acid modulates the retinoblastoma protein during adipocyte terminal differentiation. Biochim Biophys Acta 1740, 249-257.

44. Bost F, Caron L, Marchetti I, Dani C, Le Marchand-Brustel Y \& Binétruy B (2002) Retinoic acid activation of the ERK pathway is required for embryonic stem cell commitment into the adipocyte lineage. Biochem J 361, 621-627. 